\title{
Comparative Evaluation of Some Commercial Clopidogrel Tablets Available in Yemen
}

\author{
Bassam Abduh Ali ${ }^{*}$, Mohammed Gameel Al-haddad ${ }^{2}$, Abdullah Ahmed Areqi ${ }^{3}$
}

1. Department of Pharmaceutics, Faculty of Pharmacy, University of Science and Technology, Taiz Branch, Yemen

2. Department of Pharmaceutics, Faculty of Pharmacy, University of Science and Technology, Hodaidah Branch, Yemen

3. Department of Pharmacology, Faculty of Pharmacy, University of Science and Technology, Hodiadah, Yemen

Corresponding author: Bassam Abduh Ali: Email: bassam00001@yahoo.com

\begin{abstract}
Clopidogrel is a medication to reduce the risk of heart disease and taken orally. Quality of drug characterizes the production process and every phamaceutical company strives for it but often it is very difficult to achieve. This study was to investigate quality control parameters of some marketed Clopidogrel tablets. To assess the quality, eight different marketed brands of Clopidogrel $75 \mathrm{mg}$ tablets available in Yemeni market collected from different pharmacies in Hodeida city. Different quality parameters like weight variation, hardness, thickness and friability were determined according to established protocols. Then the in-vitro dissolution test, potency, disintegration time were also carried out. UV-spectrophotometer was used to determine the percentage released and assay at $218 \mathrm{~nm}$. All the brands comply the requirements of Pharmacopoeia as they showed acceptable weight variation range. Friability of all brands was less than $1 \%$ and no significant differences in disintegration times as they disintegrated within 15 minutes. In case of dissolution profile, all brands except C6 showed acceptable dissolution time as they released more than $60 \%$ of drug in 45 minute. The hardness of only two brands was within the range. All brands also meet the potency specifications. This study suggested that most commercially Clopidogrel tablets in Yemen maintain the quality and comply with the pharmacopeia specifications.
\end{abstract}

Keywords: Clopidogrel, Physicochemical, Dissolution profile, Potency.

\section{INTRODUCTION}

Quality of a product is an important factor in supporting the marketing of commercial drug products as well as patient compliance. Quality assurance processes may range from the performance of simple chemical experiments, which determine the identity and screening for the presence of particular pharmaceutical substance to more complicated requirements of pharmacopoeial monographs. It can be achieved by following some parameters that are specified in the respective monograph of the drug (Hasan et al., 2013).
United States of Pharmacopeia and British Pharmacopeia are such two Pharmacopeias that provide the necessary specifications.

Quality is essential for the survival and growth of the organization and customer satisfications. As a result, there will be development of belief on the customer's mind about the product of that company which is an important criterion for the survival and growth of the organization (Nasrin et al., 2011). If the quality of the product is low then there will be increased return of the product from the market and then profitability and customer 
loyalty are decreased (Lamba et al., 2010). There are two types of tests, compendial and non-compendial tests (Anderson et al., 2009; Yarkala et al., 2012).

Clopidogrel is a novel thienopyridine inhibitor of adenosine diphosphate (ADP)induced platelet activation as in figure (1). Clopidogrel is a routine component of the clinical management of patients after acute coronary syndrome. It is approved for the reduction of atherosclerotic events in patients with stroke, myocardial infection, cardiovascular disease and acute coronarysyndrome (Yarkala et al., 2012).

The objective of this study is to ensure conformity of quality for some different commercially available brands of Clopidogrel tablets in Yemeni market, to ensure the significant difference between expensive and economic product through effectiveness. This study is also conducted to obtain a brief idea about physico-chemical parameters of those brands.

\section{METHODS}

Standard Clopidogrel powder was kindly supplied as a gift from Bio-pharm (Yemen). The eight brands Clopidogrel tablets were purchased from different pharmacies in Hodeida city in Yemen.

\section{Recruitment of sample product}

The available marketed samples of eight brands (more than 20 tablets of each brand) of Clopidogrel tablet were purchased from different retail pharmacies at Hodeida city in Yemen. These tablets of eight brands were coded as C1, C2, C3, C4, C5, C6, C7 and C8. The samples were checked for their physical appearance, name of manufacturer, batch number, and manufacturing date, expiry date, manufacturing license number and maximum retail price at the time of purchase.

\section{Evaluation of the selected products thickness and diameter measurement}

Thickness and diameter of 10 tablets formulations were measured using thickness micrometer (GT.Tools, India) and mostly (2 - 4)mm (Gunda, 2015).

\section{Hardness test}

The crushing strength of the tablet was measured using automatic hardness tester (LIH-1, USA). At first 10 tablets were picked randomly from 20 tablets. Force has been applied with the screw thread and spring until the tablets has been fractured (Kamal, 2012).

\section{Friability test}

Friability test to evaluate the ability of tablet to withstand abrasion during packaging, handling \& transporting. Twenty Clopidogrel tablets were taken randomly \& weighted together. Clopidogrel tablets were then placed into the friability tester ( PTF $10 \mathrm{E}$, Germany), subjected to $100 \mathrm{rpm}$ for 1 minute ( $25 \mathrm{rpm}$ for 4 minutes) and were reweighted. The loss of weight indicates the friability and the percent of weight loss was calculated (Gomez et al., 2004).

\section{Weight variation test}

For each brand, 20 tablets were randomly and weighted individually using an analytical balance and the average weights were then determined (Chouhan et al., 2016).

\section{Disintegration test}

The disintegration test is carried out in an apparatus (PTWS 100D, Germany) containing a basket rack assembly with six glass tubes of $7.75 \mathrm{~cm}$ in length and $9 \mathrm{~mm}$ in diameter, the bottom of which consists of a (\#10) mesh sieve. The basket is raised and lowered 28-32 times per minute in a medium of $900 \mathrm{ml}$ phosphate buffer $\mathrm{PH}=6.8$ which is maintained at $37 \pm 2{ }^{\circ} \mathrm{C}$. Six tablets were placed in each of the tubes and 
the time required for complete passage of tablet fragments through the mesh was considered as the disintegration time of the tablet (Gibson, 2001; Monographs, 2002).

\section{Potency test}

Dissolve an accurately weighed quantity of Clopidogrel reference in $0.1 \mathrm{~N}$ $\mathrm{HCl}$ to get $0.0075 \mathrm{mg} / \mathrm{ml}$ solution of Clopidogrel determined $\lambda_{\max }$ (Rao et al., 2014). Then 4 tablets of Clopidogrel were grinded and then transferred $75 \mathrm{mg}$,add about $100 \mathrm{ml}$ of $0.1 \mathrm{~N} \mathrm{HCL}$ and stir for about 20 minutes to dissolve, filter the solution and diluted and then absorbance was measured at $218 \mathrm{~nm}$ ( Suhas et al.,2011). The percentage of drug content was calculated according to standard calibration curve (Cazedey et al., 2012).

\section{Dissolution and drug release}

The experimental conditions are, medium is phosphate buffer solution $\mathrm{pH}$ 6.8, apparatus is paddle method (USP apparatus I, Erweka TD6R, Germany) and the temperature is kept constant $37 \pm 2^{\circ} \mathrm{C}$. Dissolution test was carried out using $900 \mathrm{ml}$ of phosphate buffer solution at a paddle speed of $50 \mathrm{rpm}$ for 45 minutes. The samples ( $5 \mathrm{ml})$ were taken at $0,5,15,25,35$ and 45 minutes interval, filtered and diluted suitably; it was replaced by same amount of the fresh medium each time. Absorbance of the resulting solution was measured 218 $\mathrm{nm}$ against phosphate buffer solution $\mathrm{pH}$ 6.8 as a blank. The amount of released drug was calculated using standard calibration curve (USP, 2004).

\section{Data analysis}

All determinations and calculation in the study were carried out with the use of a Microsoft Excel 2010.

\section{RESULTS AND DISCUSSION Thickness and diameter}

Thickness of the tablet is inversely proportional to hardness i.e. increase in the thickness decrease hardness \& vice versa. Very thick tablet affects packaging either in blister or plastic container. In general, thickness and diameter are controlled within 5 percent of average value (USP, 2004). So, from the results of the thickness of the different tablet brands it was observed that all the tested tablets had deviation less than 5\% and they were uniform in their thickness and acceptable limit (Table I) and (Figures 2 and 3 ).

\section{Hardness test}

If the tablet is too hard, it may not disintegrate in the required period and if it is too soft, it will not withstand the handling during subsequent processing such as coating or packaging and shipping operations (Gupta KA et al., (2010). Hardness was monitored using an automatic tablet hardness tester and the results were tabulated (Table I) and (Figure 4). Hardness range specification is (5-8) kgs (USP, 2016). Only three brands C1, C3 and C6 fulfill the specification of this test by the average value of hardness (5.87 $\pm 0.229),(5.86 \pm 0.366)$ and $4.87 \pm 0.531$ respectively that were within the acceptable range.

\section{Friability test}

The USP specification for friability test is 1\% (Nushrat et al., 2017). It was monitored that eight different brands of Clopidogrel tablets were in accordance with guideline (Table I) and (Figure 5).

\section{Weight variation determination}

Tablet weight is mainly affected by factors such as tooling of the compression machine, head pressure, machine speed and flow properties of the powder. Weight variation test was done to check the uniformity of contents and active ingredients so that a uniform product can be guaranteed with an elegant appearance. The tested tablets showed uniformity of weight except brand C3 and C7 that were out the within the compendia limit 
Table I. Hardness, Friability, Thickness and Diameter results of different brands of Clopidogrel tablets

\begin{tabular}{|c|c|c|c|c|}
\hline Tablet code & $\begin{array}{c}\text { Hardness (Kg) } \\
\pm \text { SD }\end{array}$ & $\begin{array}{c}\text { Friability (\%) } \\
\pm \text { SDD }\end{array}$ & $\begin{array}{c}\text { Thickness }(\mathrm{mm}) \\
\pm \text { SD }\end{array}$ & $\begin{array}{l}\text { Diameter } \\
(\mathrm{mm}) \pm \mathrm{SD}\end{array}$ \\
\hline C1 & $5.87 \pm 0.229$ & $0.045 \pm 0.029$ & $4.48 \pm 0.028$ & $8.65 \pm 0.006$ \\
\hline C2 & $3.39 \pm 0.114$ & $0.067 \pm 0.102$ & $3.19 \pm 0.065$ & $8.08 \pm 0.022$ \\
\hline C3 & $5.86 \pm 0.366$ & $0.036 \pm 0.019$ & $4.65 \pm 0.182$ & $10.31 \pm 0.045$ \\
\hline C4 & $2.91 \pm 0.316$ & $0.371 \pm 0.102$ & $3.12 \pm 0.020$ & $7.89 \pm 0.042$ \\
\hline C5 & $3.66 \pm 0.135$ & $0.198 \pm 0.097$ & $2.56 \pm 0.056$ & $6.56 \pm 0.016$ \\
\hline C6 & $4.87 \pm 0.531$ & $0.061 \pm 0.076$ & $4.33 \pm 0.101$ & $8.22 \pm 0.043$ \\
\hline C7 & $2.09 \pm 0.312$ & $0.380 \pm 0.110$ & $2.06 \pm 0.023$ & $8.21 \pm 0.049$ \\
\hline C8 & $3.71 \pm 0.396$ & $0.082 \pm 0.068$ & $4.47 \pm 0.022$ & $8.64 \pm 0.011$ \\
\hline
\end{tabular}

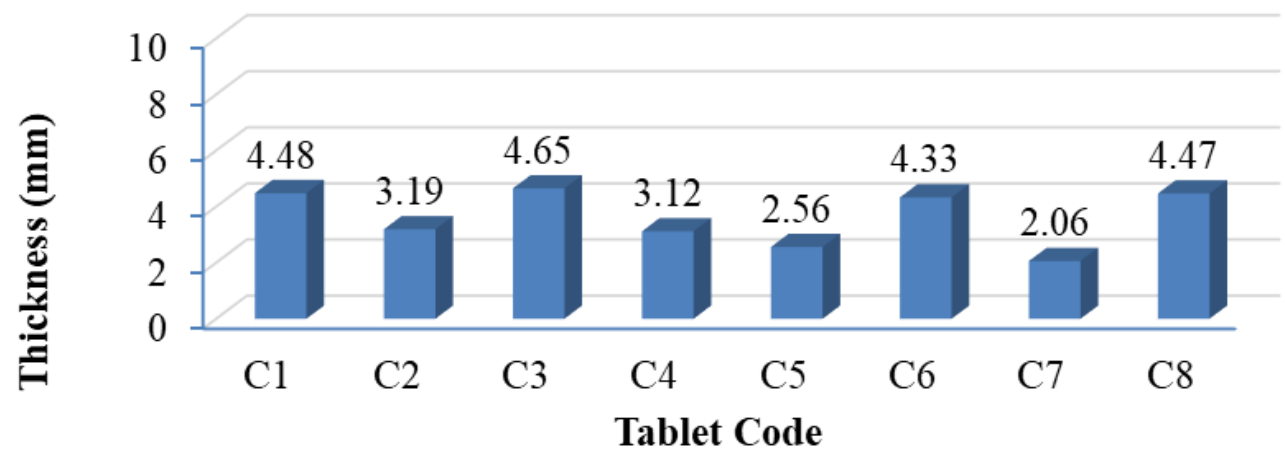

Figure 2. Thickness measurements of different brands of Clopidogrel tablets

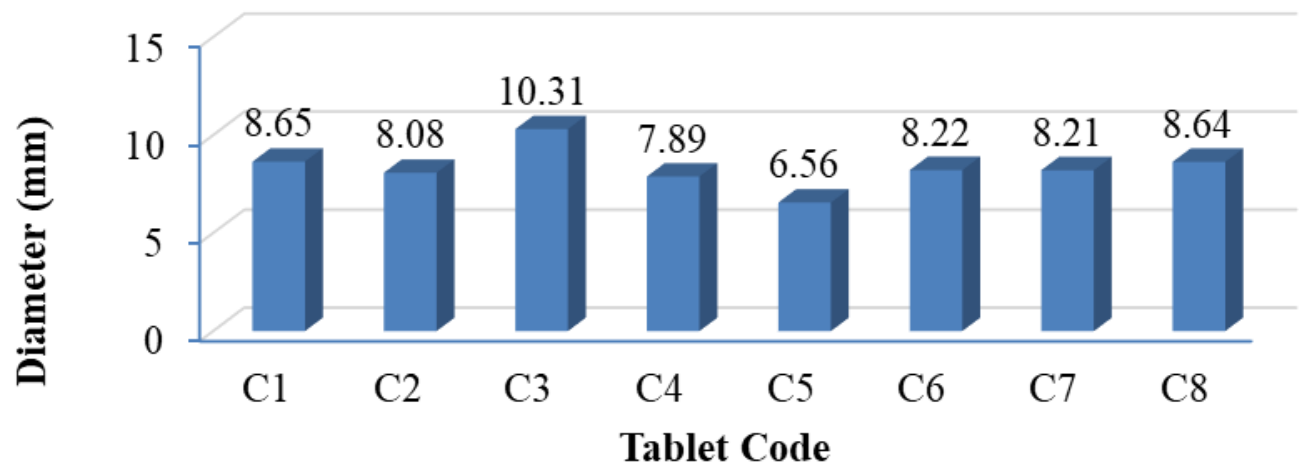

Figure 3. Diameter measurements of different brands of Clopidogrel tablets

according to USP specifications (Table II) and represented in (Figure 6) (Kishore et al., 2013).

\section{Disintegration test}

Disintegration test is very important for tablet because the dissolution rate of drug depends on it, which ultimately affect the rate of absorption of drug (Kumar et al., 2013). Also if the disintegration time is not uniform in a set of samples being analyzed, it indicates batch inconsistency and lack of batch uniformity. According to USP, the specification of disintegration time requirements 5 to 30 minutes (Table II) and (Figure 7), it was noticed that all the tablets 


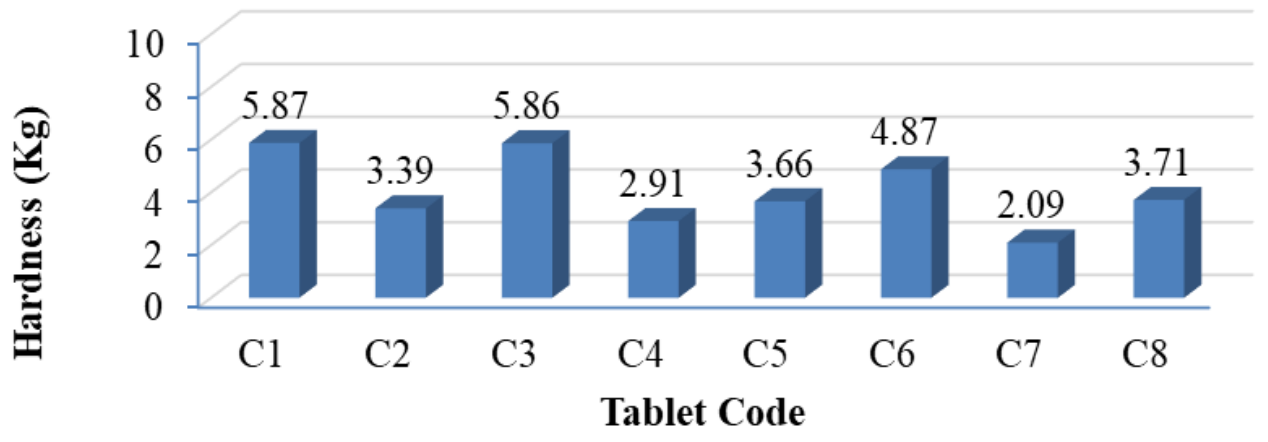

Figure 4. Hardness data of different brands of Clopidogrel tablets

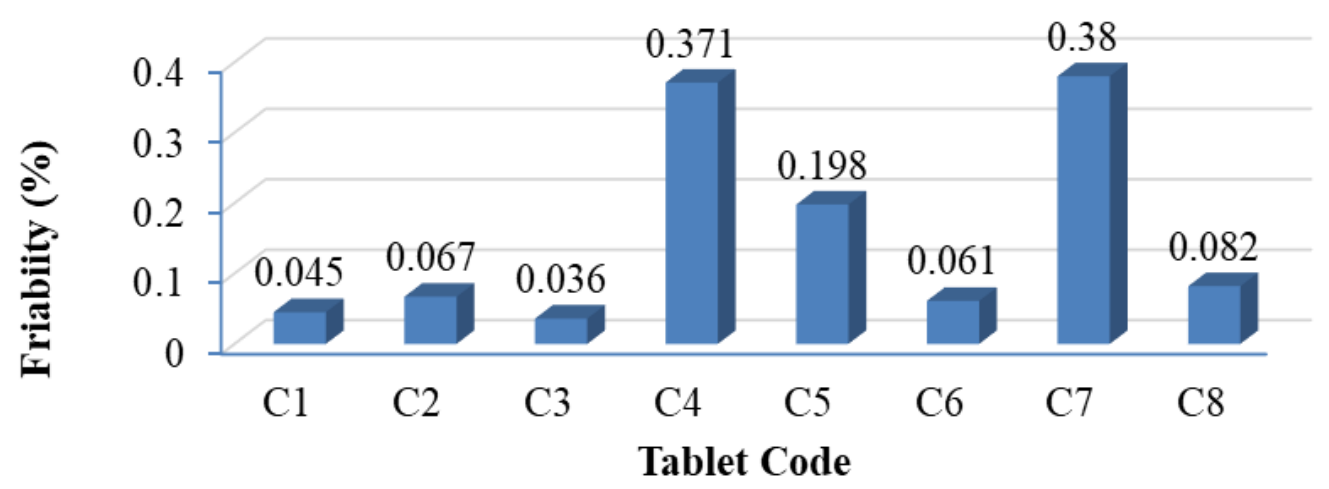

Figure 5. Friability data of different brands of Clopidogrel tablets

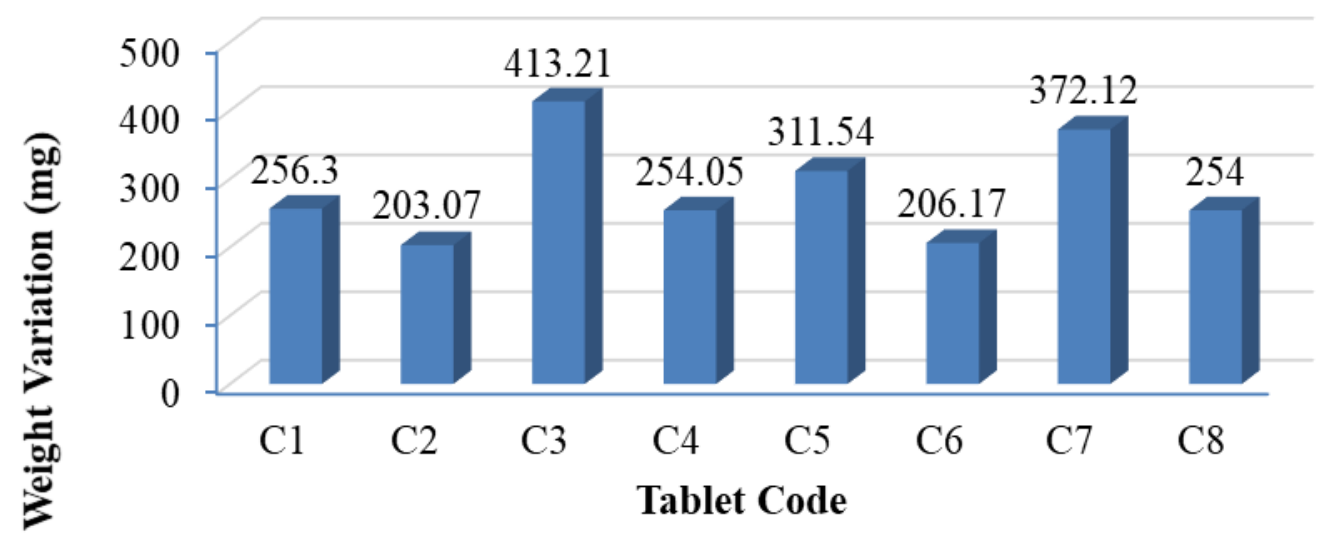

Figure 6. Weight variation of different brands of Clopidogrel tablets

of different brands that have been tested are within the limit.

\section{Potency test}

The percentage content of Clopidogrel tablet should comply with the specification because very highly potent drug may give toxic effect and very less potent drug may give sub-therapeutic effect. Potency of all brands was found within $85.34 \pm 0.03-130.05 \pm 0.02 \%$. USP specification for the drugs are equivalent to not less than $95.00 \%$ and not more than $105.00 \%$. Only three brands are within the limit of potency according to the USP specification that were $\mathrm{C} 1, \mathrm{C} 5$ and $\mathrm{C} 6$ 
Table II. Weight variation, Potency and Disintegration time of different brands of Clopidogrel tablet

\begin{tabular}{cccc}
\hline Tablet code & $\begin{array}{c}\text { Weight variation } \\
(\mathbf{m g}) \pm \text { SD }\end{array}$ & Potency (\%) \pm SD & $\begin{array}{c}\text { Disintegration time } \\
\text { (min) } \pm \text { SD }\end{array}$ \\
\hline C1 & $256.30 \pm 4.17$ & $96.10 \pm 0.05$ & $13.30 \pm 1.19$ \\
C2 & $203.07 \pm 3.32$ & $130.05 \pm 0.02$ & $5.42 \pm 0.24$ \\
C3 & $413.21 \pm 6.77$ & $107.21 \pm 0.07$ & $2.14 \pm 0.77$ \\
C4 & $254.05 \pm 3.65$ & $85.34 \pm 0.03$ & $6.21 \pm 0.92$ \\
C5 & $311.54 \pm 6.62$ & $96.21 \pm 0.06$ & $8.06 \pm 1.33$ \\
C6 & $206.17 \pm 5.91$ & $103.87 \pm 0.09$ & $2.45 \pm 0.56$ \\
C7 & $372.12 \pm 5.89$ & $112.04 \pm 0.10$ & $7.22 \pm 1.04$ \\
C8 & $254.00 \pm 4.29$ & $115.11 \pm 0.03$ & $12.01 \pm 1.17$ \\
\hline
\end{tabular}

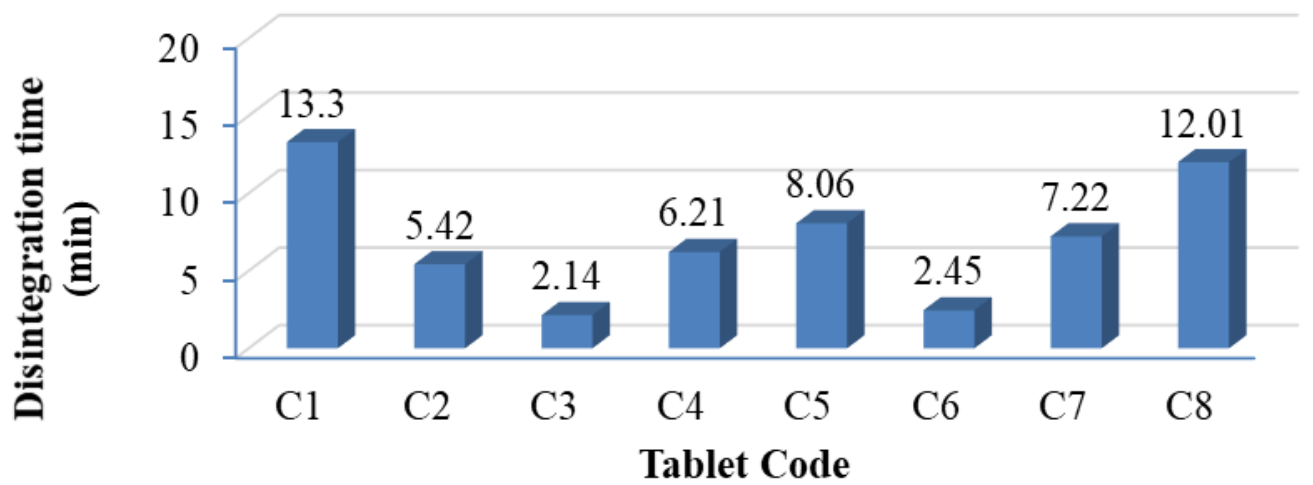

Figure 7. Disintegration time of different brands of Clopidogrel tablets

as observed (Table II) and (Figure 8).

\section{Dissolution test}

The drug release study is a measure of the amount of the drug released into the dissolution medium over time. This study gives an idea of amount of drug available for absorption after oral administration

The results of the in vitro release of branded tablets (Table III) and (Figure 9). By the end (45 minutes) of the in-vitro release test, the percentage drug released for brands C1, C2 , C3, C4, C5, C6, C7, and C8 was found to $104.01,75.21,88.53,65.00$, $72.00,39.56,60.06$ and $115.00 \%$ respectively. The USP specification of Clopidogrel is not less than $60 \%$ of the labeled amount dissolved in 45 minutes.
The results obtained from the study revealed that all the brands released the drug more than $60 \%$ except $\mathrm{C} 6$ that not passed this test.

Table IV showed the rank order of branded tablets according to quality control tests. From this table the brands of Clopidogrel tablets can be arranged in a descending manner as shown.

\section{CONCLUSION}

All the tested brands of Clopidogrel $75 \mathrm{mg}$ tablets complied with the official quality specifications. By comparing the quality results, the best brand was $\mathrm{C} 1$ while C7 was the worst. Clopidogrel tested tablet have uniform weight and also sufficient physical stability to maintain physica 
Table III. In vitro release profile for different brands of Clopidogrel $75 \mathrm{mg}$ tablets

\begin{tabular}{ccccccccc}
\hline Time & \multicolumn{7}{c}{ Percent of drug release (\%) \pm SD } \\
\cline { 2 - 9 } (min) & C1 & C2 & C3 & C4 & C5 & C6 & C7 & C8 \\
\hline 0 & $0.00 \pm$ & $0.00 \pm$ & $0.00 \pm$ & $0.00 \pm$ & $0.00 \pm$ & $0.00 \pm$ & $0.00 \pm$ & $0.00 \pm$ \\
& 0.00 & 0.00 & 0.00 & 0.00 & 0.00 & 0.00 & 0.00 & 0.00 \\
5 & $30.21 \pm$ & $13.74 \pm$ & $19.93 \pm$ & $15.09 \pm$ & $18.05 \pm$ & $06.06 \pm$ & $14.93 \pm$ & $25.07 \pm$ \\
& 0.54 & 1.23 & 1.12 & 0.76 & 1.05 & 1.13 & 0.87 & 0.32 \\
15 & $52.51 \pm$ & $28.56 \pm$ & $35.45 \pm$ & $28.42 \pm$ & $35.12 \pm$ & $17.94 \pm$ & $25.08 \pm$ & $65.76 \pm$ \\
& 2.17 & 3.21 & 2.45 & 0.55 & 2.73 & 1.09 & 0.65 & 0.54 \\
25 & $73.37 \pm$ & $45.23 \pm$ & $52.67 \pm$ & $38.21 \pm$ & $40.42 \pm$ & $22.08 \pm$ & $37.11 \pm$ & $86.33 \pm$ \\
& 3.90 & 0.98 & 0.87 & 0.34 & 1.05 & 2.11 & 1.21 & 0.34 \\
35 & $89.61 \pm$ & $62.05 \pm$ & $71.32 \pm$ & $46.06 \pm$ & $57.23 \pm$ & $30.43 \pm$ & $45.43 \pm$ & $97.06 \pm$ \\
& 2.13 & 3.09 & 1.43 & 0.21 & 0.87 & 1.97 & 3.08 & 2.06 \\
45 & $104.01 \pm$ & $75.21 \pm$ & $88.53 \pm$ & $65.11 \pm$ & $72.90 \pm$ & $39.56 \pm$ & $60.06 \pm$ & $115.00 \pm$ \\
& 0.12 & 0.22 & 0.34 & 0.98 & 0.97 & 0.70 & 2.06 & 0.03 \\
\hline
\end{tabular}

Table IV. Rank order of branded tablets according to quality control tests

\begin{tabular}{|c|c|c|c|c|c|c|c|c|}
\hline Test & C1 & C2 & C3 & C4 & C5 & C6 & C7 & $\mathrm{C8}$ \\
\hline Weight variation & 3 & 1 & 8 & 2 & 7 & 6 & 5 & 4 \\
\hline Thickness & 4 & 6 & 8 & 1 & 5 & 7 & 3 & 2 \\
\hline Diameter & 1 & 4 & 7 & 5 & 3 & 6 & 8 & 2 \\
\hline Hardness & 1 & 6 & 2 & 7 & 5 & 3 & 8 & 4 \\
\hline Friability & 2 & 4 & 1 & 7 & 6 & 3 & 8 & 5 \\
\hline Disintegration & 8 & 3 & 1 & 4 & 6 & 2 & 5 & 7 \\
\hline Dissolution & 2 & 4 & 3 & 6 & 5 & 8 & 7 & 1 \\
\hline Total rank order & 21 & 28 & 30 & 32 & 37 & 35 & 44 & 25 \\
\hline Conclusive rank order & 1 & 3 & 4 & 5 & 7 & 6 & 8 & 2 \\
\hline
\end{tabular}

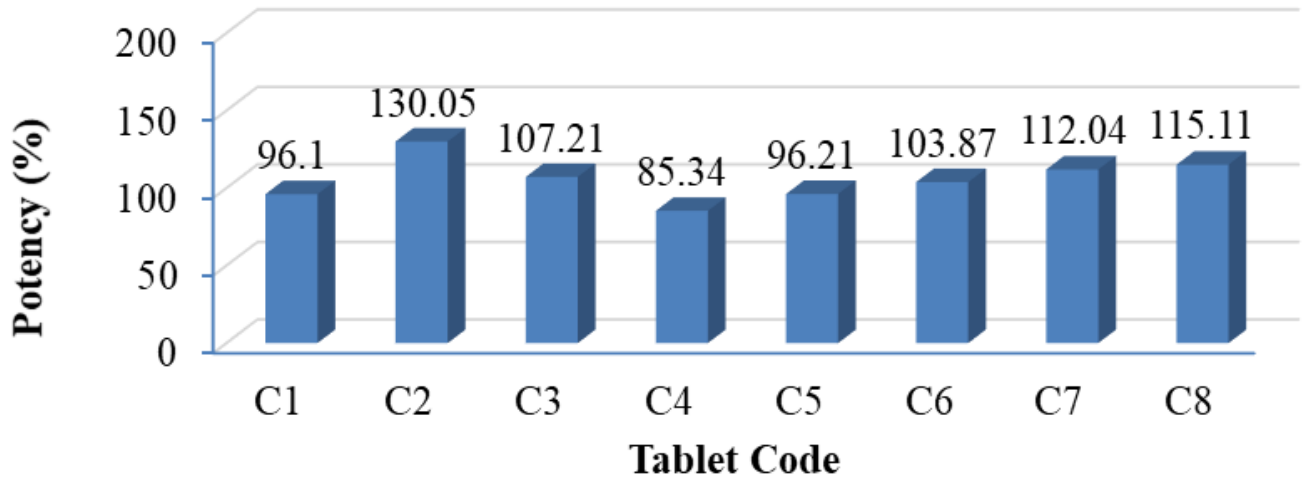

Figure 8. Potency of different brands of Clopidogrel tablets

integrity over time and they will also be capable of with standing the stiffness of mechanical shock confrontation in its production, packaging, shipping and dispensing. It also concluded that all most products passed the pharmacopeial specifications with different levels. 


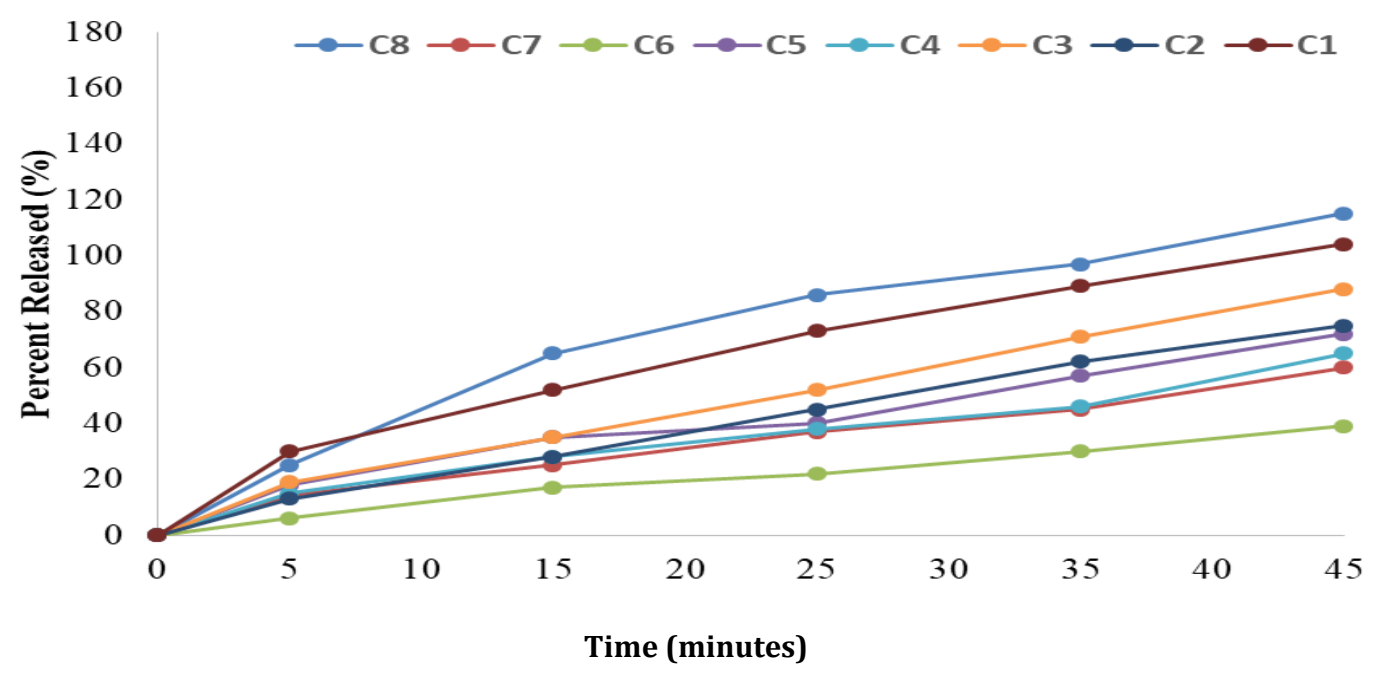

Figure 9. In vitro release profile for different brands of Clopidogrel $75 \mathrm{mg}$ tablets

\section{AKNOWLEDGEMENT}

All praises for the student and management of UST - Hodaida branch, for funding a large part of this research.

\section{REFERENCES}

Abdel Naser Zaid., Rowa' Al Ramahi., Rana Bustami and Ayman Mousa., (2015), Comparative fasting bioavailability of two clopidogrel formulations in healthy Mediterranean volunteers: an in vitro-in vivo correlation, Drug Design, Development and Therapy,9 ,2359-2365.

Anderson., G. S. Tablets. In L. Lachman., H. A. Lieberman., \& J. Kanig., (2009) The theory and practice of industrial pharmacy. Bombay: Varghese publishing house. (pp. 293-345).

Cazedey., E. C. L., \& Salgado., H. R. N. (2012). Spectrophotometric determination of ciprofloxacin hydrochloride in ophthalmic solution. Advances in Analytical Chemistry, 2(6), 74-79.

Chouhan, A., Marothia, D., Ranka, K., \& Rathore, K. S. (2016). Formulation and Evaluation of Extended Release Tablets of Metformin $\mathrm{HCl}$.

Gibson, (2001), Pharmaceutical preformulation and formulation. HIS Health group, Englewood.
Gomez, Y., Adams, E., \& Hoogmartens, J. (2004). Analysis of purity in 19 drug product tablets containing clopidogrel: 18 copies versus the original brand.Journal of pharmaceutical and biomedical analysis, 34(2), 341-348.

Griffin, R.(2012). Management. New York: Houghton Mifflin Company.

Gunda, R. K. (2015). Formulation development and evaluation of rosiglitazone maleate sustained release tablets using 32 factorial design. IJPTR, 8, 713-24.

Gupta KA (2010) Introduction to Pharmaceutics-I. Cbs Publishers \& Distributors, New Delhi (India), Pp: 344-398.

Hasan A., Dewan SAR., Ahamed SK., Kai MM (2013) Quality control studies on cetirizine hydrochloride tablets available in Bangladesh drug market. International Journal of Pharmacy and Biological Sciences 3(1): 349-354.

Kamal, S. (2012). Evaluation of Quality Control Parameters of Two Brands of Diazepam Tablets (Doctoral dissertation, East West University).

Kanij ND1., Lovely Z1., Abdul A1., Sanjida H2., Sabrin IK3 and Sharmeen A4 (2017), Comparative In Vitro Quality 
Evaluation of Some Clopidogrel Tablets, Commercially Available in Bangladesh Drug Market. Bioequiv \& Bioavailab Int J 1(3): 000117.

Karch, A. M. (2014). Lippincott's nursing drug guide. Philadelphia: Wolters Kluwer Health/Lippincott Williams \& Wilkins.

Kishore N., Singh A., Reddy N (2013) Formulation and Evaluavation of Clopidogrel Bisulfate Immediate Release Tablets. International Journal of Life Sciences 1(1): 11-18.

Kumar K., Vijayakumar K., Reddy N (2013) Clopidogrel an Overview. International journal of Pharmacology science 3(1): 1-7.

Lamba, S. S.(2010), Pharmaceutical Facilities New Concept in Facility Design. Eisai (pp. 1-28).

Monographs, O. (2002). United States Pharmacopeia-National Formulary (USP 25-NF 20). Rockville, Maryland: United States Pharmacopeial Convention Inc.

Nasrin N., Asaduzzaman M., Mowla R., Rizwan F., Alam A (2011) A comparative study of physical parameters of selected ketorolac tromethamine tablets available in the pharma market of Bangladesh. Journal of applied phramceutical Sciences 1(8): 101-103.
Nushrat SA., Nasreen W., Deepa KN (2017) In vitro comparative study of quality control parameter of some brand of ketorolac tablets available in Bangladesh. World journal of pharmacy and pharmaceutical science 6(8): 146-155.

Rao, K. R. K., \& Lakshmi, K. R. (2014). Design, development and evaluation of clopidogrel bisulfate floating tablets. International Journal of Pharmaceutical Investigation, 4(1), 19-26.

Suhas Gurav., Rohan Tembare., Vishali Salunkhe., Devprakash, Senthilkumar G.P.(2011), Spectrophotometric determination of clopidogrel bisulfate in pharmaceutical formulations. American Journal of PharmTech Research. 1(4): 258-263.

United State Pharmacopeia ( USP) (2004) 27 United State Convention : pp. 2622-2625.

United States Drug Enforcement Administration.

Benzodiazepinesarticle available at http: //www.justice.gov/dea / concer $\mathrm{n} /$ benzodiazepines.

Yarkala S., Sivakumar A., Sameer G., (2012), Physico-Chemical Studies on Stability of Clopidogrel Tablet Formulations. International Journal of Pharmaceutical and Biological Science 3(4): 433-439. 